\title{
Emergência e crescimento inicial de plântulas de Inga ingoides (Rich.) Willd. em função de posições e profundidades de semeadura
}

\author{
Emergency and initial growth of seedlings of Inga ingoides (Rich.) \\ Willd. in function of the position and depth of sowing
}

\author{
Eduardo Maciel Oliveira Laime ${ }^{1}$; Edna Ursulino Alves ${ }^{2 *}$; Roberta Sales Guedes ${ }^{3}$; \\ Kelina Bernardo Silva ${ }^{3}$; Dayane Cristine de Souza Oliveira ${ }^{1}$; Sueli da Silva Santos ${ }^{1}$
}

\section{Resumo}

O ingá (Inga ingoides (Rich.) Willd.) é uma frutífera muito utilizada em reflorestamento de matas ciliares e na alimentação humana. Com o objetivo de verificar o efeito da posição e profundidade de semeadura na emergência e crescimento inicial de plântulas, foi realizado o experimento em delineamento inteiramente ao acaso, com quatro repetições de 25 sementes, dispostos em esquema fatorial $3 \times 6$ (posições e profundidades). Os tratamentos consistiram em diferentes posições das sementes no substrato: hilo voltado para cima, formando um ângulo de $0^{\circ}$ em relação a um eixo imaginário perpendicular ao nível do substrato; hilo para o lado, formando um ângulo de $90^{\circ}$ em relação ao eixo imaginário e hilo voltado para baixo, formando um ângulo de $180^{\circ} \mathrm{em}$ relação ao eixo imaginário, nas profundidades de $1,2,3,4,5$ e $6 \mathrm{~cm}$. Determinou-se o teor de água, a porcentagem de emergência, primeira contagem e índice de velocidade de emergência, bem como o comprimento e a massa seca de plântulas. A melhor profundidade de semeadura de I. ingoides variou de acordo com as posições, sendo as adequadas de 4 cm com o hilo voltado para baixo; 2,68-3,0 cm com o hilo para cima e $1 \mathrm{~cm}$ para as sementes, com o hilo para o lado.

Palavras-chave: Ingá, qualidade de sementes, frutífera nativa

\begin{abstract}
The inga (Inga ingoides (Rich.) Willd.) has edible fruits and is also used in riparian reforestation. The objective was to study the effect of the position and the depth of sowing in the emergence and initial growth of Inga seedlings. The experiment was accomplished with a completely randomized design, with four replications of 25 seeds, loaded in a $3 \times 6$ (positions and depths) factorial outline. The treatments were: hilum upwards, forming a $0^{\circ}$ angle in relation to a perpendicular imaginary axis at the level of the substrate; hilum sideways, forming an angle of $90^{\circ}$ in relation to the imaginary axis and hilum downwards, forming an angle of $180^{\circ}$ in relation to the imaginary axis. The tested depths were: $1,2,3$, 4,5 and $6 \mathrm{~cm}$. The evaluations were: emergence, first count, index of speed emergence, length and dry mass of the seedlings. The depth of sowing of I. ingoides varied in agreement with the positions, being the best results down of $4 \mathrm{~cm}$ deep with the hilum downwards, 2,68-3,0 $\mathrm{cm}$ deep with the hilum upwards and $1 \mathrm{~cm}$ deep for the seeds, with the hilum sideways.
\end{abstract}

Key words: Inga, seed quality, viability, native fruit

\footnotetext{
1 Alunos de Graduação em Agronomia do Departamento de Fitotecnia e Ciências Ambientais, CCA-UFPB- Universidade Federal da Paraíba, Areia - PB. E-mail: edu_laime@hotmail.com; dayane_pathy@hotmail.com; suelidasilvasantos@yahoo.com.br

2 Prof ${ }^{a}$. Adjunta do Departamento de Fitotecnia e Ciências Ambientais, CCA - UFPB; Caixa Postal 02, CEP: 58.3987-000, Areia - PB. E-mail: ednaursulino@cca.ufpb.br

3 Doutorandas em Agronomia, Departamento de Fitotecnia e Ciências Ambientais, CCA-UFPB- Universidade Federal da Paraíba. E-mail: roberta_biologa09@yahoo.com.br; kelinabernardo@yahoo.com.br

* Autor para correspondência
} 


\section{Introdução}

Com grande área de mata nativa, o Brasil possui uma grande variedade de árvores frutíferas com potencial econômico ainda pouco estudadas. Muitas destas espécies, com potencialidades de aproveitamento, são pouco exploradas devido à falta de estudos que permitam a implantação de pomares comerciais (MALUF; BILIA; BARBEDO, 2003).

$\mathrm{O}$ ingazeiro (Inga ingoides (Rich.) Willd.) é uma frutífera ocasionalmente cultivada para fins paisagísticos, em reflorestamento de áreas degradadas, sombreamento e para alimentação humana. Em seu habitat natural, na floresta atlântica em todo o Brasil, seu porte é arbóreo com 5 a 10 metros de altura. As inflorescências são em racemos axilares solitários, formadas de agosto a novembro, cujos frutos são legumes cilíndricos e indeiscentes, densopubescentes, com poucas sementes envoltas por arilo flocoso de sabor doce (LORENZI, 2004). Suas sementes, que têm o fenômeno da viviparidade, possuem elevada percentagem de germinação, porém, extrema sensibilidade à desidratação (recalcitrantes) (MATA, 2006).

A esta frutífera são atribuídas várias utilidades, como por exemplo, o sombreamento (em cultivos de café e cacau), lenha, composição de formações florestais heterogêneas, com produção de fitomassa voltada à geração de energia, fonte alimentar, estabilização de solos ácidos e fitoterapia (BILIA et al., 2003).

Dentre os fatores que influenciam o processo germinativo devem ser considerados, além da qualidade da semente, a intensidade de dormência, a velocidade de germinação que pode ser influenciada por vigor da semente, temperatura e umidade do substrato, posição e profundidade de semeadura (URBEN FILHO; SOUZA, 1993). Em cultivo com a utilização de propagação sexuada, a profundidade e a posição de semeadura devem ser adequadas para garantir a germinação das sementes, a emergência e o desenvolvimento das plântulas (MARTINS et al., 1999).
A profundidade de semeadura é específica para cada espécie e quando adequada, propicia germinação e emergência de plântulas uniformes (SOUSA et al., 2007). Profundidades de semeaduras excessivas podem impedir que a plântula ainda frágil emerja à superfície do solo. Conforme Marcos Filho (2005) as semeaduras muito profundas podem também aumentar o período de suscetibilidade a patógenos. Contudo, se as semeaduras forem superficiais as sementes ficarão expostas a qualquer alteração ambiental, como excesso ou déficit hídrico ou térmico, podendo originar plântulas pequenas e fracas (TILLMANN et al., 1994), além de facilitar o ataque de predadores ou danos decorrentes da irrigação, e a exposição da radícula, causando sua destruição (JELLER; PEREZ, 1997).

Para Prunus brasiliensis Schott ex Spreng, Sturion (1980) recomendou as profundidades entre 0,5 e $1 \mathrm{~cm}$, enquanto a percentagem de emergência de plântulas de Zizyphus joazeiro Mart cresceu à medida que se aumentou a profundidade de semeadura, atingindo o máximo de $88 \%$ em $1,6 \mathrm{~cm}$ (ALVES et al., 2008).

Da mesma maneira, também há posições de semeadura que são melhores para a germinação, a emergência e o desenvolvimento das plântulas (MARTINS; CARVALHO, 1993). A posição da semente no substrato pode reduzir a germinação e/ou afetar negativamente o desenvolvimento inicial da plântula, como foi verificado em Euterpe espiritosantensis (MARTINS et al., 1999) e Oenocarpus mapora (NASCIMENTO et al., 2002). A posição da semente também pode favorecer positivamente a germinação, como foi observado em Astrocaryum aculeatum Meyer (ELIAS; FERREIRA; GENTIL, 2006), Euterpe oleraceae Mart. (SILVA e SILVA et al., 2007), Cedrela fissilis L. (SANTOS et al., 2008) e Amburana cearensis (Allemão) A.C. Smith (GUEDES, 2009). Por outro lado, a posição da semente pode não influenciar o processo germinativo, como se verificou na emergência de plântulas de Moringa oleifera Lam. (SOUSA et al., 2007). 
Diante do exposto, objetivou-se determinar a posição e a profundidade de semeadura que proporcionemmelhoremergênciaedesenvolvimento às plântulas de $I$. ingoides.

\section{Material e Métodos}

O experimento foi conduzido no Laboratório de Análise de Sementes (LAS) e em casa de vegetação, no Centro de Ciências Agrárias, da Universidade Federal da Paraíba (CCA - UFPB), localizado em Areia - PB. Para a obtenção das sementes foram coletados frutos maduros de I. ingoides, diretamente de árvores localizadas no CCA - UFPB, os quais foram acondicionados em sacos plásticos e conduzidos ao LAS para beneficiamento mediante debulha manual das vagens.

Após o beneficiamento as sementes, com sarcotesta, foram postas para secar sobre folhas de papel toalha em condições ambientais de laboratório (temperatura média de $24,5 \pm 0,5^{\circ} \mathrm{C}$ e umidade relativa média de $78 \pm 3 \%$ ) por um período de 12 horas, conforme determinações preliminares. Decorrido o período de secagem, a sarcotesta foi retirada e as sementes foram submetidas aos testes de vigor.

\section{Teste de emergência}

Para as avaliações dos efeitos das posições e profundidades de semeadura, quatro repetições de 25 sementes foram semeadas em bandejas plásticas com dimensões de $0,45 \times 0,30 \times 0,07 \mathrm{~m}$, contendo como substrato areia lavada e esterilizada em autoclave. Os tratamentos consistiram em diferentes posições (sementes com o hilo voltado para cima $\mathrm{HC}$, formando um ângulo de $0^{\circ}$ em relação a um eixo imaginário perpendicular ao nível do substrato, sementes com o hilo de lado, formando um ângulo de $90^{\circ}$ em relação ao eixo imaginário - HL e sementes com o hilo voltado para o baixo, formando um ângulo de $180^{\circ}$ em relação ao eixo imaginário - HB) e profundidades de semeadura $(1,2,3,4,5$ e $6 \mathrm{~cm})$. As avaliações do número de plântulas emergidas foram diárias, seguindo-se preferencialmente o mesmo horário. O teste foi conduzido em casa de vegetação, sem controle de temperatura e umidade, durante 20 dias. As irrigações foram feitas diariamente até se verificar o início da drenagem natural.

\section{Primeira contagem de emergência}

A primeira contagem foi realizada juntamente com o teste de emergência, a qual consistiu na porcentagem de plântulas emergidas aos nove dias após a semeadura, com comprimento médio do epicótilo de dois centímetros.

\section{Índice de velocidade de emergência (IVE)}

Foi determinado mediante contagem diária do número de plântulas emersas durante 20 dias e o índice determinado de acordo com a fórmula proposta por Maguire (1962).

\section{Comprimento e massa seca de plântulas}

Após a contagem final do teste de emergência, as plântulas normais foram submetidas a medições da parte aérea e raiz primária com auxílio de uma régua graduada em centímetro. Em seguida, separaram-se as raízes e parte aérea, as quais foram postas para secar em estufa regulada a $65^{\circ}$ até peso constante (48 horas) e, decorrido esse período, pesadas em balança analítica com precisão de 0,001g (VIEIRA; CARVALHO, 1994).

\section{Análise estatística e delineamento experimental}

O delineamento utilizado foi inteiramente casualizado, em esquema fatorial $3 \times 6$, sendo três posições e seis profundidades de semeadura, em quatro repetições de 25 sementes. Os dados obtidos foram submetidos à análise de variância, utilizandose o teste $\mathrm{F}$ para comparação dos quadrados médios e as médias comparadas pelo teste de Scott - Knott a $5 \%$ de probabilidade. Para os efeitos quantitativos foi realizada análise de regressão polinomial. 


\section{Resultados e Discussão}

A profundidade de $4,18 \mathrm{~cm}$ proporcionou às plântulas de I. ingoides melhor resposta para a porcentagem de emergência, quando as sementes foram semeadas com o hilo voltado para baixo (HB), sendo observado um percentual de 100\% de emergência. As sementes semeadas com o hilo voltado para cima (HC) foram responsáveis por $72 \%$ de plântulas emergidas, na profundidade de $2,68 \mathrm{~cm}$. Já na posição do hilo para o lado (HL), verificouse que o percentual de plântulas que emergiram reduziu linearmente à medida que se aumentou a profundidade de semeadura (Figura 1).

O sucesso na germinação da semente e no estabelecimento inicial da plântula no campo está relacionado, principalmente, a alguns fatores como o contato da semente com o solo mineral, deslocamento do ponto de semeadura, semeadura muito profunda, alagamento ou excesso de umidade, seca e perdas de sementes e plântulas para insetos e pássaros (DOUGHERTY, 1990).
O aumento da barreira física proporcionado pelas camadas mais profundas (acima de $3 \mathrm{~cm}$ para sementes semeadas com o hilo para cima e acima de $4 \mathrm{~cm}$ quando semeadas com o hilo para baixo) foi determinante para a redução da emergência das plântulas, provavelmente pelo fato de as sementes terem consumido suas reservas na tentativa de superar essa barreia, pois segundo Tillmann et al. (1994) em profundidades excessivas, particularmente nas espécies de sementes menores, ocorre impedimento à emergência da plântula por ausência de energia suficiente para tal.

A maior porcentagem de emergência de plântulas oriundas de sementes com o hilo para baixo provavelmente se deve ao fato de não haver necessidade de movimentos da radícula para se fixar no substrato, uma vez que a mesma emerge próxima ao hilo. Tal hipótese está fundamentada em relatos de Carvalho e Nakagawa (2000) ao comentarem que quando há necessidade da realização do movimento rotatório é possível que existam posições em que as sementes são semeadas que facilitem ou que dificultem a emergência de plântulas.

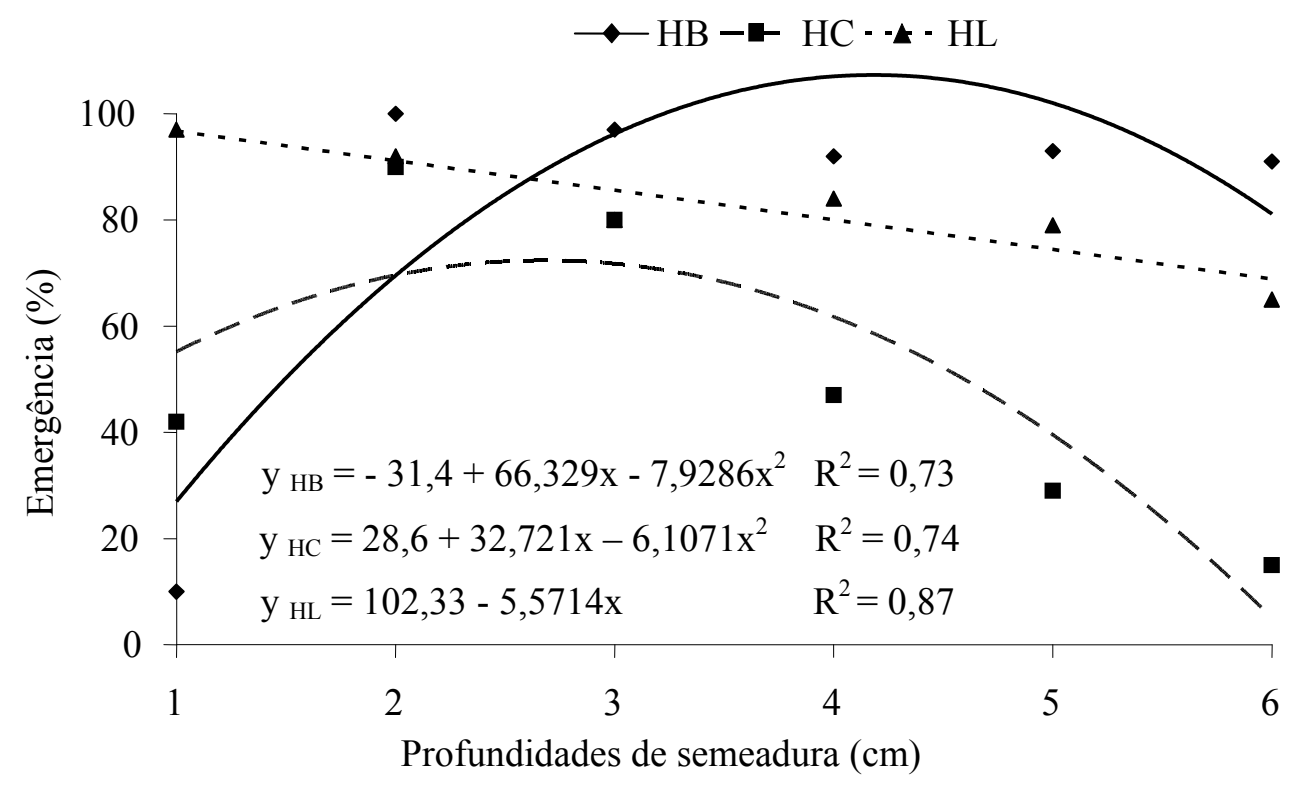

Figura 1. Emergência de plântulas de Inga ingoides (Rich.) Willd. em função de diferentes posições e profundidades de semeadura. HB: sementes com o hilo voltado para o baixo; HC: sementes com o hilo voltado para cima; HL sementes com o hilo de lado. 
Aemergência de plântulas de Oenocarpusmapora Karste reduziu quando as sementes foram semeadas com o hilo voltado para baixo (NASCIMENTO et al., 2002), enquanto que as plântulas de Astrocaryum aculeatum Meyer tiveram menor porcentagem de emergência quando a semeadura foi com o hilo voltado para cima (ELIAS; FERREIRA; GENTIL, 2006) e, para sementes de Moringa oleifera Lam. a profundidade ideal foi de dois centímetros (SOUSA et al., 2007).

Para Cedrela fissilis L. a posição mais adequada para semeadura foi sementes com o hilo voltado para baixo e com $2,17 \mathrm{~cm}$ de profundidade (SANTOS et al., 2008). As sementes de Erythrina velutina Willd. semeadas com o hilo para baixo expressaram a emergência máxima ( $99 \%$ ) na profundidade de 1,82cm (CARDOSO et al., 2008). Profundidades de semeadura iguais ou superiores a três centímetros são inadequadas para Euterpe oleracea Mart. (SILVA e SILVA et al., 2007), enquanto para Amburana cearensis (Allemão) A.C. a profundidade de $3,5 \mathrm{~cm}$ e a posição do hilo voltado para baixo foram as melhores condições para emergência (GUEDES, 2009).

Os dados da primeira contagem de emergência das plântulas originadas de sementes com o hilo para baixo (HB) e hilo para cima (HC) não se ajustaram a modelos de regressão, obtendo valores médios de 26 e $2 \%$, respectivamente (Figura 2). Com relação às sementes semeadas com o hilo para o lado (HL) averiguou-se que, com o aumento das profundidades de semeadura houve uma diminuição significativa nos percentuais de plântulas emergidas na primeira contagem, atingindo valores nulos de emergência após $4 \mathrm{~cm}$ de profundidade.

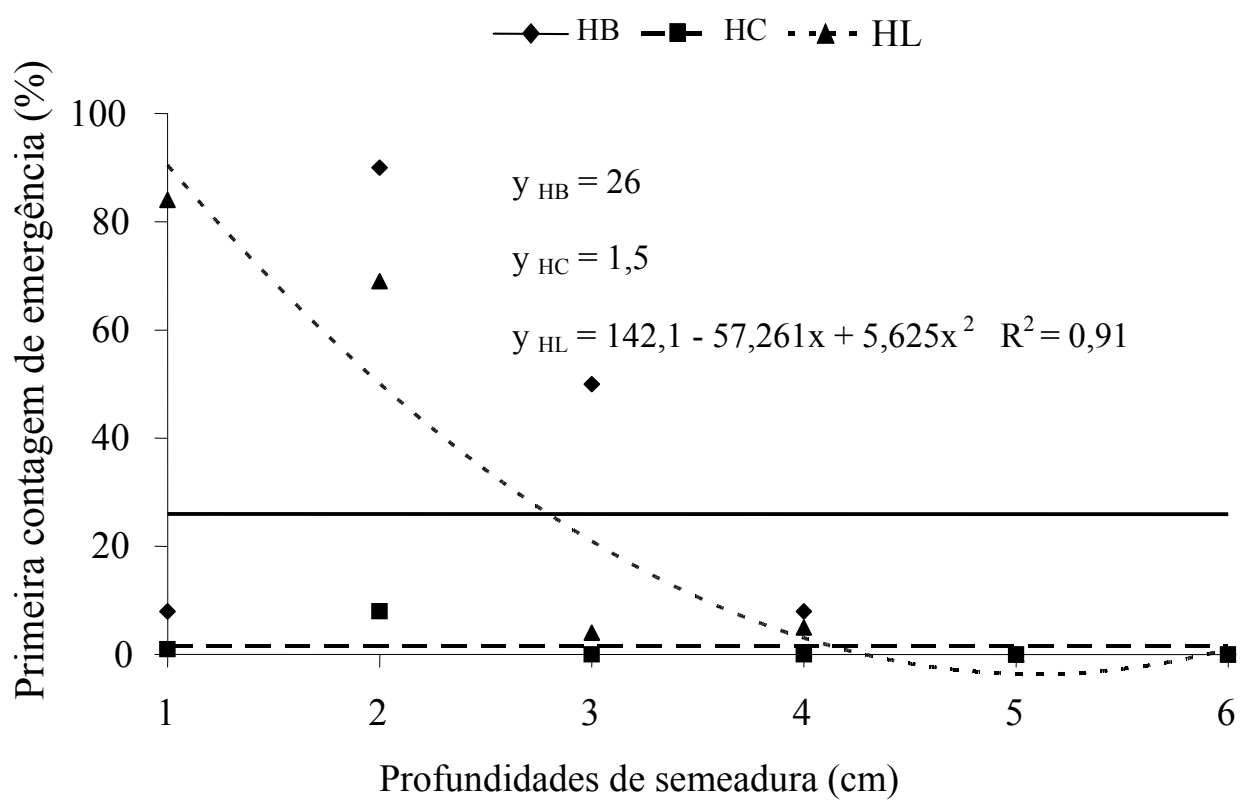

Figura 2. Primeira contagem de emergência de plântulas de Inga ingoides (Rich.) Willd. em função de diferentes posições e profundidades de semeadura. HB: sementes com o hilo voltado para o baixo; HC: sementes com o hilo voltado para cima; HL sementes com o hilo de lado. 
Esses resultados devem-se, provavelmente, a um maior consumo das reservas das sementes para conversão em energia para que as plântulas conseguissem romper o impedimento físico constituído pelo substrato. Tais resultados estão de acordo com Mendonça, Ramos e Pio (2007) quando relataram que, nas maiores profundidades de semeadura, as sementes de Annona muricata L. devem ter sofrido um desgaste fisiológico maior até a emergência, podendo, nestes casos, dar origem a plântulas mais debilitadas e, conseqüentemente, com menor capacidade de sobrevivência no período subseqüente. Alves et al. (2008) relataram que para a primeira contagem de emergência de plântulas de
Zizyphus joazeiro Mart. houve uma redução de 12,4\% na porcentagem de emergência, a cada centímetro de aumento na profundidade de semeadura.

Com relação ao índice de velocidade de emergência (Figura 3), registrou-se que apenas os dados das sementes com o hilo para cima (HC) e hilo para o lado (HL) se ajustaram a modelo de regressão, onde nas sementes com o hilo para o lado (HL) registrou-se redução no IVE a partir de $1 \mathrm{~cm}$, enquanto naquelas com o hilo para cima (HC) os índices começaram a reduzir a partir de $3 \mathrm{~cm}$. O valor médio do índice de velocidade de emergência de plântulas originadas das sementes posicionadas com hilo para baixo (HB) foi de 1,85 (Figura 3).

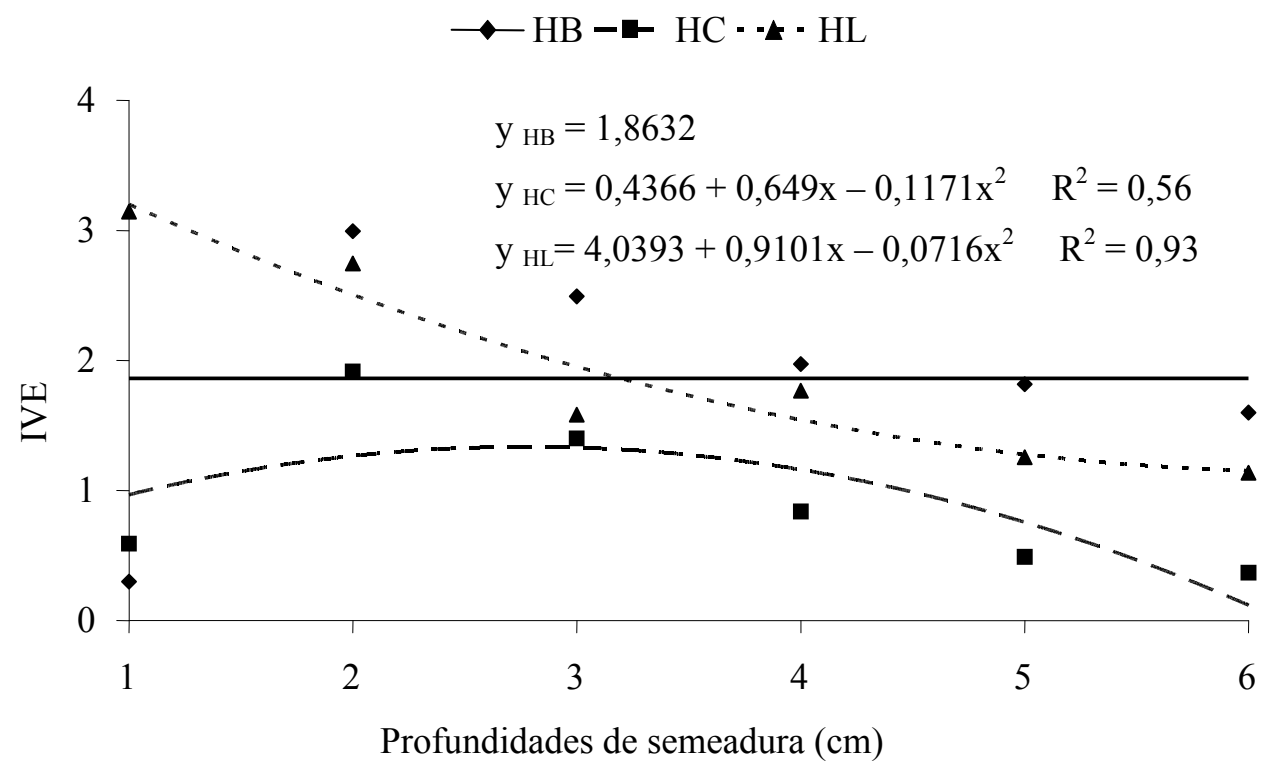

Figura 3. Índice de velocidade de emergência (IVE) de plântulas de Inga ingoides (Rich.) Willd. em função de diferentes posições e profundidades de semeadura. HB: sementes com o hilo voltado para o baixo; HC: sementes com o hilo voltado para cima; HL sementes com o hilo de lado.

De acordo com Martins et al. (1999), a semeadura na posição correta proporciona rápida germinação e velocidade de emergência das plântulas, as quais se tornam menos vulneráveis as condições adversas do meio por emergirem mais rápido no solo e passarem menos tempo nos estágios iniciais de desenvolvimento. $\mathrm{O}$ índice de velocidade de emergência das plântulas de Euterpe espiritosantensis Fernandes foi maior quando as sementes foram postas para germinar com o hilo para cima (MARTINS et al., 1999). Plântulas de Oenocarpus mapora Karsten, tiveram redução do IVE quando originadas de unidades de dispersão posicionada com o hilo para baixo (NASCIMENTO et al., 2002). 
O aumento da profundidade de semeadura reduziu significativamente a velocidade de emergência de plântulas de Bidens pilosa L. (MUNIZ FILHO et al., 2004). Para sementes de Moringa oleifera Lam. o IVE foi favorecido quando semeadas com o ápice voltado para cima ou deitada (SOUSA et al., 2007). A posição do hilo voltado para baixo beneficiou a emergência de plântulas de Cedrela fissilis L.
(SANTOS et al., 2008) e Amburana cearensis (Allemão) A.C. (GUEDES, 2009).

Pelos resultados contidos na Figura 4 constatouse que os dados referentes ao comprimento da raiz primária não se ajustaram a modelos de regressão, sendo que os comprimentos médios foram de 6,93 para as sementes posicionadas com o hilo para cima; 9,31 para sementes com o hilo voltado para baixo e 9,82 cm para sementes com o hilo para o lado.

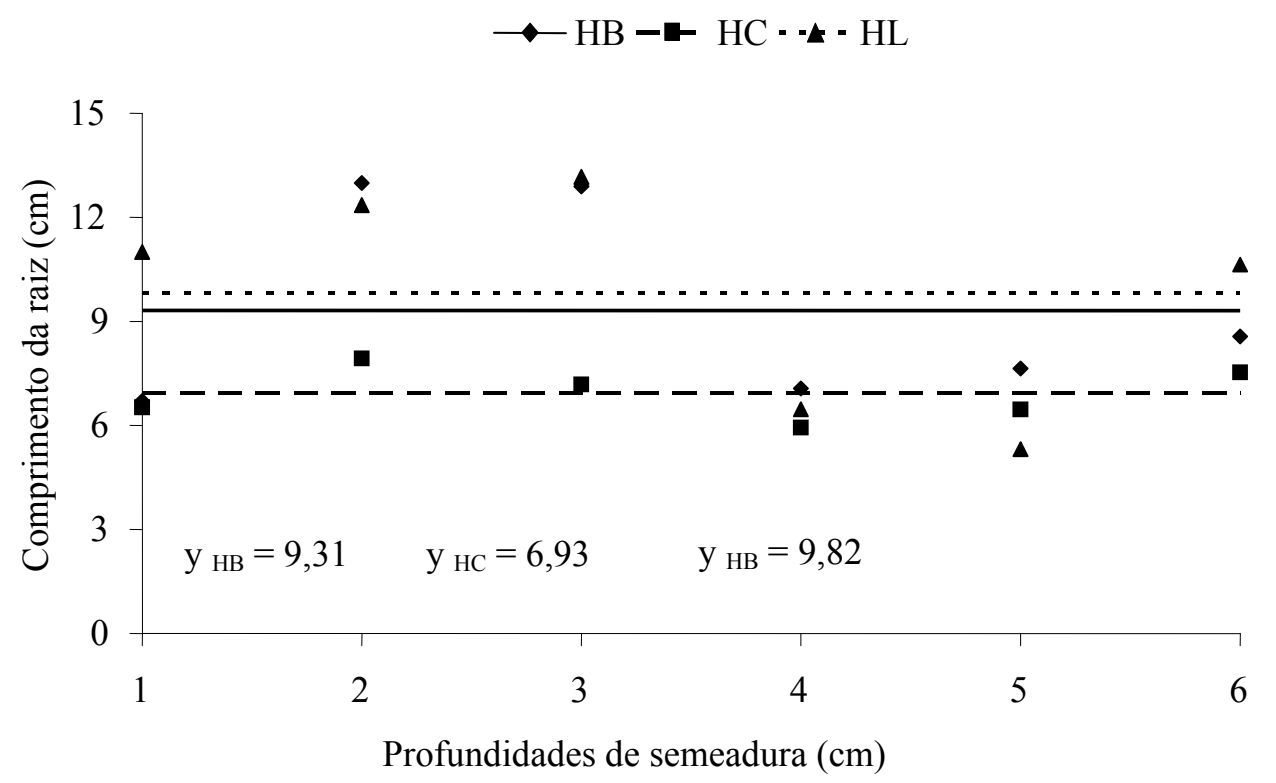

Figura 4. Comprimento da raiz primária de plântulas de Inga ingoides (Rich.) Willd. oriundas de sementes submetidas a diferentes posições e profundidades de semeadura. HB: sementes com o hilo voltado para o baixo; HC: sementes com o hilo voltado para cima; HL sementes com o hilo de lado.

Com o aumento da profundidade de semeadura as sementes exigem mais água, oxigênio e temperatura adequada para seu desenvolvimento normal (SACCO, 1976). As diferentes posições de semeadura (semente com ápice para cima, deitada e ápice para baixo) não influenciaram o comprimento da raiz primária de plântulas de Moringa oleifera Lam. (SOUSA et al., 2007). No entanto, Alves et al. (2008) verificaram uma redução de $1,22 \mathrm{~cm}$ no comprimento das plântulas de Zizyphus joazeiro Mart., a cada centímetro de aumento na profundidade de semeadura.
Quanto ao comprimento da parte aérea (Figura 5) nota-se que nas sementes com hilo voltado para cima (HC) e para o lado (HL) ocorreu aumento linear no seu comprimento à medida que a semeadura foi mais profunda, enquanto que com o hilo para baixo não houve ajuste dos dados a modelos de regressão, cujo comprimento médio foi de $5,85 \mathrm{~cm}$. Em semeaduras mais superficiais, normalmente, as sementes ficam mais sujeitas às variações ambientais, podendo originar plântulas pequenas e fracas (TILLMANN et al., 1994). Nascimento et al. (2002) testaram diferentes posições de semeadura em sementes de 
Oenocarpus mapora Karsten e constataram que a parte aérea das plântulas oriundas das unidades de dispersão semeadas com a rafe na horizontal e para baixo foi prejudicada, obtendo-se os menores comprimentos.

A massa seca das raízes de plântulas de I. ingoides (Figura 6), oriundas de sementes semeadas com o hilo para o lado (HL) e hilo para baixo (HB) reduziu significativamente à medida que foi aumentando a profundidade da semeadura. Entretanto, quando semeadas com o hilo para cima (HC) os dados da massa seca das raízes não se ajustaram a modelos de regressão, cujo conteúdo médio de massa seca foi de $0,023 \mathrm{~g}$.

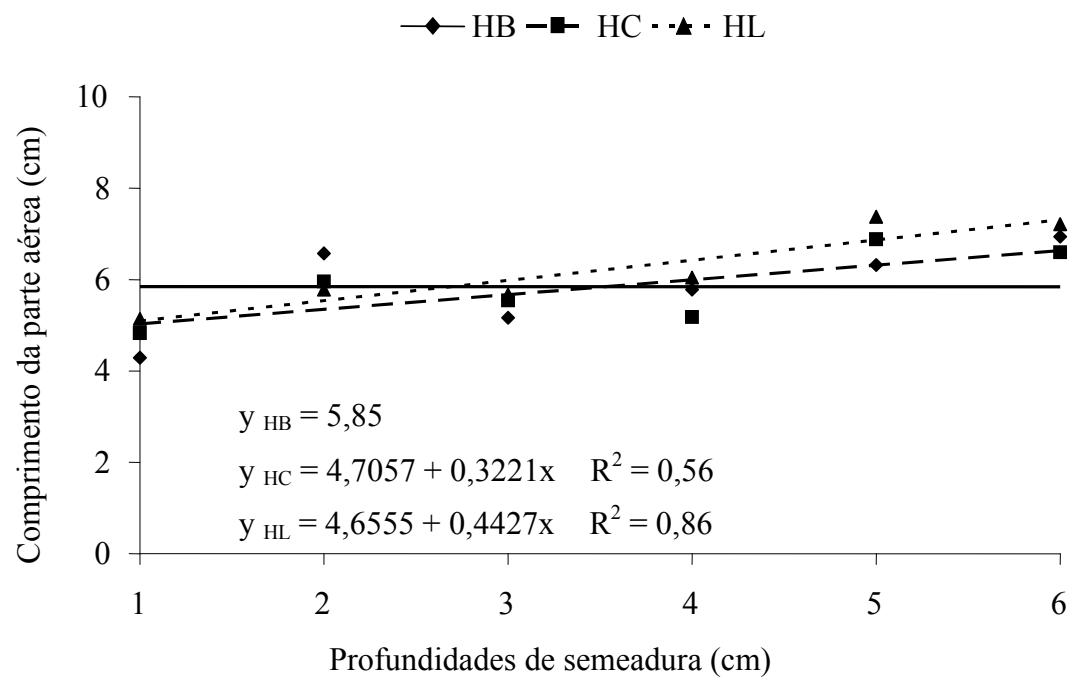

Figura 5. Comprimento da parte aérea de plântulas de Inga ingoides (Rich.) Willd. oriundas de sementes submetidas a diferentes posições e profundidades de semeadura. HB: sementes com o hilo voltado para o baixo; HC: sementes com o hilo voltado para cima; HL sementes com o hilo de lado.

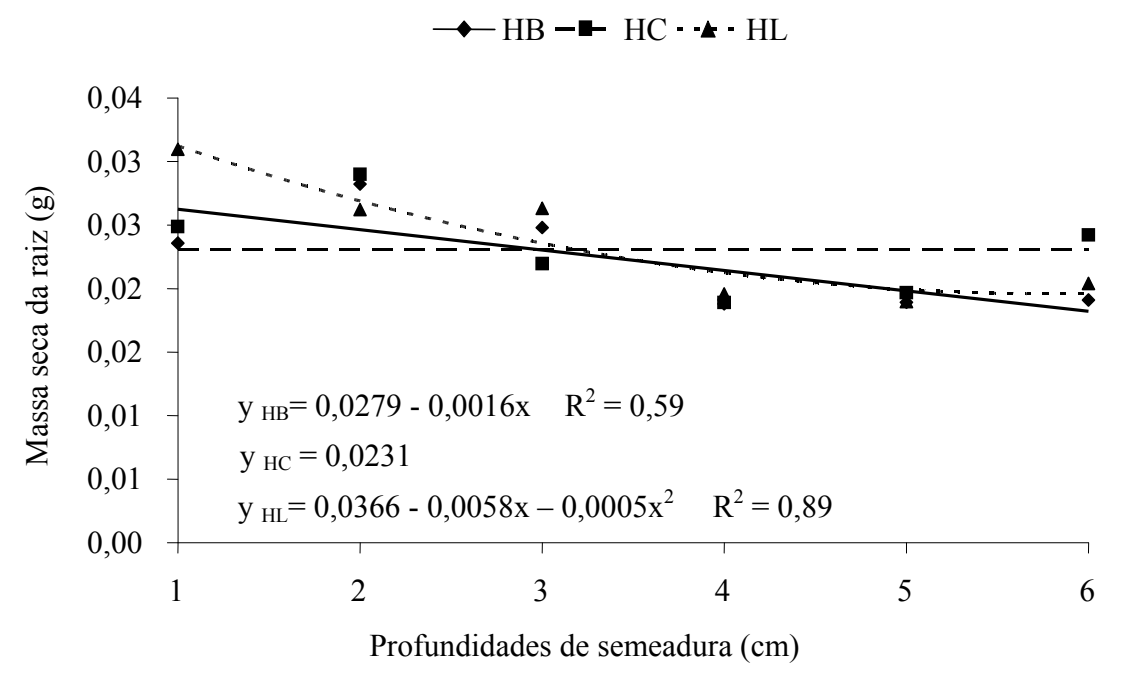

Figura 6. Massa seca das raízes de plântulas de Inga ingoides (Rich.) Willd. oriundas de sementes submetidas a diferentes posições e profundidades de semeadura. HB: sementes com o hilo voltado para o baixo; HC: sementes com o hilo voltado para cima; HL sementes com o hilo de lado. 
Com relação à massa seca da parte aérea (Figura 7), quando as sementes foram semeadas com o hilo voltado para cima (HC) houve um decréscimo do conteúdo de massa seca das plântulas resultantes à medida que foi aumentando a profundidade da semeadura. No entanto, quando a semeadura foi com o hilo para baixo (HB) e hilo para o lado (HL) os dados da massa seca da parte aérea não se ajustam a modelos de regressão, com valores médios de 0,031 e $0,035 \mathrm{~g}$, respectivamente.

Para Adenanthera pavonina L., Fanti e Perez (1995) observaram diminuição significativa da porcentagem de plântulas emergidas e do peso da massa seca das mesmas com o aumento da profundidade de semeadura. Para Citrus limonia Osbeck, as posições de semeadura (semente deitada, com ápice para cima e para baixo) não influenciaram a massa seca das raízes e parte aérea, uma vez que não houve diferenças significativas entre os tratamentos utilizados (ROBLES; ARÚJO; MINAMI, 2000). Para sementes de Moringa oleifera Lam. a massa seca da parte aérea não teve relação substancial com a profundidade de semeadura (SOUSA et al., 2007). Entretanto, para Zizyphus joazeiro Mart. houve uma redução de $0,015 \mathrm{~g}$ na massa seca das plântulas a cada centímetro de aumento na profundidade de semeadura (ALVES et al., 2008).

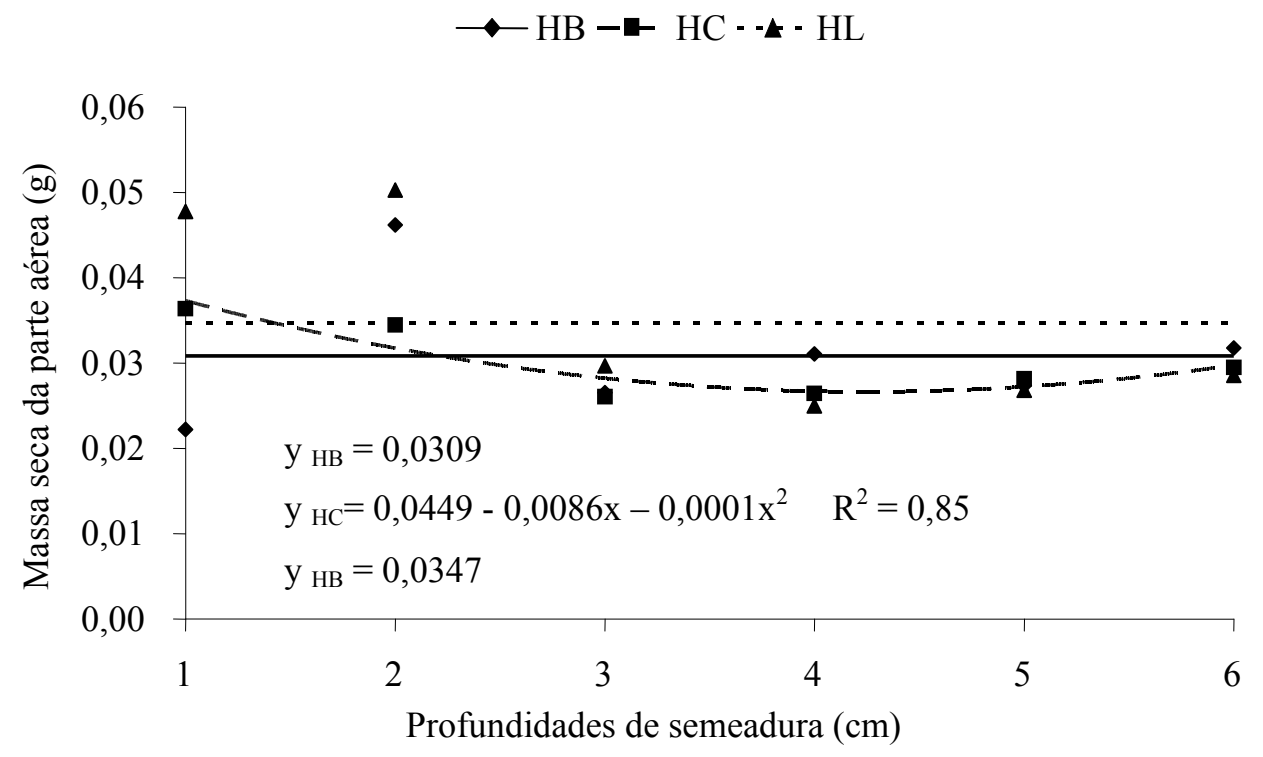

Figura 7. Massa seca da parte aérea de plântulas de Inga ingoides (Rich.) Willd. oriundas de sementes submetidas a diferentes posições e profundidades de semeadura. HB: sementes com o hilo voltado para o baixo; HC: sementes com o hilo voltado para cima; HL sementes com o hilo de lado.

\section{Conclusão}

A profundidade de semeadura de I. ingoides varia de acordo com as posições, sendo as melhores de $4 \mathrm{~cm}$ com o hilo voltado para baixo; 2,68-3,0 cm com o hilo para cima e $1 \mathrm{~cm}$ para as sementes com o hilo para o lado.

\section{Referências}

ALVES, E. U.; BRUNO, R. L. A.; ALVES, A. U.; ALVES, A. U.; CARDOSO, E. A.; DORNELAS, C. S. M.; GALINDO, E. A.; BRAGA JÚNIOR, J. M. Profundidades de semeadura para emergência de plântulas de juazeiro. Ciência Rural, Santa Maria, v. 38, n. 4, p. 1158-1161, 2008. 
BILIA, D. A. C.; BARBEDO,C. J.; CÍCERO, S. M.; MARCOS-FILHO, J. Ingá: uma espécie importante para recomposição vegetal em florestas ripárias, com sementes interessantes para a ciência. Informativo ABRATES, Brasília, v. 1, n. 13, p. 26-30, 2003.

CARDOSO, E. A.; ALVES, E. U.; BRUNO, R. L. A.; ALVES, A. U.; ALVES, A. U.; SILVA, K. B. Emergência de plântulas de Erythrina velutina em diferentes posições e profundidades de semeadura. Ciência Rural, Santa Maria, v. 38, n. 9, p. 2618-2621, 2008.

CARVALHO, N. M.; NAKAGAWA, J. Sementes: ciência, tecnologia e produção. 4. ed. Jaboticabal: FUNEP, 2000. $429 \mathrm{p}$.

DOUGHERTY, P. M. A Field investigation of the factors which control germination and establishment of loblolly pine seeds. Georgia: FRDA, Forestry Commission, 1990. 5 p. (Forestry Commission, 7).

ELIAS, M. E. A.; FERREIRA, S. A. N.; GENTIL, D. F. O. Emergência de plântulas de tucumã (Astrocaryum aculeatum) em função da posição de semeadura. Acta Amazonica, Manaus, v. 36, n. 3, p. 385-388, 2006.

FANTI, S. C.; PEREZ, S. C. J. G. A. Efeito do estresse hídrico e da luminosidade na germinação de Adenanthera pavonina L. (olho-de-dragão) e seu desempenho em campo. Informativo ABRATES, Londrina, v. 5, n. 2, p. 187, 1995.

GUEDES, R. S. Tecnologia de sementes de Amburana cearensis (Allemão) A.C. Smith. 2009. Dissertação (Mestrado em Agronomia) - Departamento de Fitotecnia e Ciências Ambientais. Universidade Federal da Paraíba, Areia.

JELLER, H.; PEREZ, S. C. J. G. A. Efeito da salinidade e semeadura em diferentes profundidades na viabilidade e no vigor de Copaifera langsdorffii Desf. Caesalpiniaceae. Revista Brasileira de Sementes, Pelotas, v. 19, n. 2, p. 218-224. 1997.

LORENZI, H. Frutas brasileiras e exóticas cultivadas. São Paulo: Instituto Plantarum de Estudos da Flora, 2004. 127 p. v. 1.

MALUF, A. M.; BILIA, D. A. C.; BARBEDO, C. J. Drying and storage of Eugenia involucrata DC. seeds. Scientia Agricola, Piracicaba, v. 60, n. 3, p. 471-475, 2003.

MARCOS FILHO, J. Fisiologia de sementes de plantas cultivadas. Piracicaba: FEALQ, 2005. 495 p.

MARTINS, C. C.; CARVALHO, N. M. Efeito da posição da semente na semeadura sobre a emergência do feijão e da soja. Revista Brasileira de Sementes, Brasília, v. 15, n. 1, p. 63-65, 1993.
MARTINS, C. C.; GAWA, J. N.; LEÃO, M.; BOVI, A. Efeito da posição da semente no substrato e no crescimento inicial das plântulas de palmito-vermelho (Euterpe espiritusantensis Fernandes - Palmae). Revista Brasileira de Sementes, Londrina, v. 21, n. 1, p. 164-173, 1999.

MATA, M. F. Biometria e morfologia de frutos e sementes de Inga striata Benth e I. ingoides (Rich.) Willd. In: REUNIÃO NORDESTINA DE BOTÂNICA, 29., 2006, Mossoró. Anais... Mossoró, 2006. 1 CD-ROM.

MENDONÇA, W.; RAMOS, J. D.; PIO, R. Superação de dormência e profundidade de semeadura de sementes de gravioleira. Caatinga, Mossoró, v.20, n. 2, p. 73-78, 2007.

MUNIZ FILHO, A.; CARNEIRO, P. T.; CAVALCANTI, M. L. F.; ALBUQUeRQUe, R. C. Capacidade de emergência de picão-preto em diferentes profundidades de semeadura. Revista de Biologia e Ciência da Terra, Campina Grande, v. 4, n. 1, 2004. online.

NASCIMENTO, W. M. O.; OLIVEIRA, M. S. P.; CARVALHO, J. E. U.; MÜLLER, C. H. Influência da posição de semeadura na germinação, vigor e crescimento de plântulas de bacabinha (Oenocarpus mapora karsten Arecaceae). Revista Brasileira de Sementes, Londrina, v. 24, n. 1, p. 179-182, 2002.

ROBLES, W. G. R.; ARAÚJO, P. S. R.; MINAMI, K. Desenvolvimento de plântulas de limoeiro 'cravo' relacionado a posição de semeadura. Scientia Agricola, Piracicaba, v. 57, n. 2, p. 371-373, 2000.

SACCO, J. C. Botânica de semente. In: SACCO, J. C. Curso sobre produção e tecnologia de sementes. Pelotas: Universidade de Pelotas, Faculdade de Agronomia Elizeu Maciel, Centro de Treinamento de Sul, 1976, p. 98-100.

SANTOS, S. S., MOURA, M. F., GUEDES, R. S., GONCALVES, E. P., ALVES, E. U. Emergência de plântulas de Cedrela fissilis L. em função da posição e da profundidade de semeadura In: CONGRESSO DE PESQUISA E INOVAÇÃO DA REDE NORTE NORDESTE DE EDUCAÇÃO TECNOLÓGICA, 3., 2008, Fortaleza. Anais... Fortaleza, CONNEPI, 2008. 1 CD- ROM.

SILVA e SILVA, B. M.; MÔRO, F. V.; SADER, R.; KOBORI, N. N. Influência da posição e da profundidade de semeadura na emergência de plântulas de açaí (Euterpe oleracea Mart. - Arecaceae). Revista Brasileira de Fruticultura, Jaboticabal, v. 29, n. 1, p. 187-190, 2007.

SOUSA, A. H.; RIBEIRO, M. C. C.; MENDES, V. H. C.; MARACAJÁ, P. B.; COSTA, D. M. Profundidades e posições de semeadura na emergência 
e no desenvolvimento de plântulas de moringa. Revista Caatinga, Mossoró, v. 20, n. 4, p. 56-60, 2007.

STURION, J.A. Influência da profundidade de semeadura, cobertura do canteiro e sombreamento, na formação de mudas de Prunus brasiliensis Schott ex Spreng. Boletim de Pesquisa Florestal, Colombo, n. 1. p. 50-75, 1980.

TILLMANN, M. A. A.; PIANA, Z.; CAVARIANI, C.; MINAMI, K. Efeito da profundidade de semeadura na emergência de plântulas de tomate (Lycopersicon esculentum Mill.). Scientia Agricola, Pelotas, v. 51, n. 2, p. 260-263, 1994.

URBEN FILHO, G.; SOUZA, P. I. M. Manejo da cultura da soja sob cerrado: época, densidade e profundidade de semeadura. In: ARANTES, N. E.; SOUZA, P. I. M. Cultura da soja nos cerrados. Belo Horizonte: Potafos, 1993. $535 \mathrm{p}$.

VIEIRA, R. D.; CARVALHO, N. M. Testes de vigor em sementes. Jaboticabal: FUNEP/UNESP, 1994. 164 p. 
